Bangladesh Journal of Neuroscience 2019; Vol. 35 (2): 86-94

\title{
Impact of Risk Factors on the Size of Ruptured Intracranial Saccular Aneurysms
}

\author{
SARKER MHK ${ }^{1}$, HABIB M ${ }^{2}$, SHAHIDULLAH M ${ }^{3}$, DEY SK ${ }^{4}$, ISLAM ${ }^{5}$, ISLAM MR ${ }^{6}$, DEY SK ${ }^{3}$, \\ AHMED KGU ${ }^{7}$, CHOWDHURY AH ${ }^{6}$, SHAHALY $S^{7}$, ROY LK ${ }^{1}$, HASAN MH ${ }^{1}$, EMRAN MS ${ }^{8}$, \\ CHOWDHURY $A^{9}$, AKTER $S^{1}$, HASAN $M^{9}$, ABIR K $^{1}$
}

\begin{abstract}
:
Background: Un-ruptured intracranial aneurysms (UIAs) are common and prevalence is about 2 to $8 \%$. Several studies have shown that the decision to treat un-ruptured aneurysms should not be based on aneurysm size alone. A study suggest that treatment of UIAs smaller than $7 \mathrm{~mm}$ in hypertensive patients and smokers may be beneûcial. Aim and objective: The goal of this study is analysis of correlation of age, gender, location of the aneurysm, history of hypertension and cigarette smoking, previous history of SAH with the size of ruptured aneurysms. Materials and Methods: This hospital based observational cross-sectional study was conducted in the Department of Neurology \& Neurosurgery, Dhaka Medical College Hospital (DMCH), Dhaka. Total 44 patients with SAH were taken by inclusion \& exclusion criteria. The aneurysms size, site of location and aneurysm multiplicity was assessed by three-dimensional rotational digital subtraction angiography (DSA). Results:The mean age of the study population was $49.24 \pm 11.5$. About half of the population were within 51-60 years. The male female ratio was 1:1.2. Out of 44 population, $93.2 \%$ were presented with headache, $90.9 \%$ with vomiting. In this study aneurysms mean size was $5.72 \pm 4.010 \mathrm{~mm}$. $93.2 \%$ of aneurysms were below $10 \mathrm{~mm}, 75.0 \%$ were below $7 \mathrm{~mm}$ and $50.0 \%$ below $5 \mathrm{~mm}$. Size of ruptured aneurysm is small in hypertensive population and is significant ( $p$-value 0.037). Aneurysm size was significantly ( $p$-value 0.013) smaller in case of smoker. Mean aneurysm size in hypertensive smoker population was significantly ( $p$-value-0.004) smaller than hypertensive non-smoker. Population with one risk factor had mean aneurysm size was $8.32 \pm 6.84 \mathrm{~mm}$, two risk factors had $5.26 \pm 1.86 \mathrm{~mm}$, three risk factors had 4.79 $\pm 2.05 \mathrm{~mm}$ and more than three risk factors had 2.85 \pm 1.43 . Conclusion: This study shows that more the risk factors, smaller the size of aneurysms. Therefore, history of hypertension, cigarette smoking, female sex, age and positive family history should be considered in the assessment of treatment of un-ruptured intracranial aneurysms.
\end{abstract}

Key words: SAH, risk factors, intracranial Aneurysms, aneurysms size

Introduction

Subarachnoid haemorrhage (SAH) is one kind of stroke, measuring 1 to $7 \%$ of stroke patients. SAH is responsible for $5 \%$ of stroke death ${ }^{1}$. Incidence of SAH is approximately $6-15$ per 100,000 people per year ${ }^{2}$. Up to $50 \%$ of all cases of SAH are fatal and $10-15 \%$ die before reaching hospital ${ }^{3}$. After hospital admission one-third will die, about one-

1. Md. Humayun Kabir Sarker, Resident, Department of Neurology, Dhaka Medical College, Dhaka, correspondencehimu33bd@gmail.com.

2. Professor Dr. Monsur habib and Head (Rtd), Department of Neurology, Dhaka Medical College, Dhaka

3. Dr. Md. Shahidullah,Associate professor, Department of Neurology, Bangabandhu Sheikh Mujib Medical University (BSMMU)

4. Dr. Shuvash Kanti Dey, Associate professor, Department of Neurology, Bangabandhu Sheikh Mujib Medical University (BSMMU)

5. Dr. shafiqul IslamAssociate professor, Department of Neurosurgery, Dhaka Medical College

6. Professor Dr. Md. Rafiqul Islam, Department of Neurology, Bangabandhu Sheikh Mujib Medical University, Dhaka

7. Dr. Kazi Gias Uddin Ahmed ${ }^{6}$, Associate Professor, Department of Neurology, Dhaka Medical College, Dhaka.

7. Resident, Department of Physical Medicine and Rehabilitation, Dhaka Medical College, Dhaka

8. Resident, Department of Neurology, Chittagong Medical College, Chittagong

9. Resident, Department of Neurology, Bangabandhu Sheikh Mujib Medical University (BSMMU) 
third will recover with severe disability and about one-third will have excellent recovery ${ }^{4}$. Those who survive often have neurological and cognitive impairment ${ }^{3}$. The economic impact of $\mathrm{SAH}$ is severe because it mostly affect the patients in $40 \mathrm{~s}$ and 50 s during their most productive years ${ }^{5}$. Though incidence of SAH in Bangladesh is unknown. In Kashmir, India the incidence of SAH is $13 / 100000^{6}$. Bangladesh is culturally, religiously almost same as Kashmir.

Cerebral aneurysms are the most common cause of non-traumatic subarachnoid hemorrhage and is responsible for 70 to $75 \%$ of spontaneous $\mathrm{SAH}^{7}$. Ruptured "Berry" aneurysm is the most common among the aneurysmal SAH and is responsible for $85 \%$ of cases $^{8}$.

In a univariate analysis, family history of $\mathrm{SAH}$, systemic hypertension, cigarette smoking and regular alcohol consumption were significant risk factors for aneurysmal SAH. In a multivariate analysis, after adjustment for other risk factors, family history of $\mathrm{SAH}$, cigarette smoking and hypertension remained significant ${ }^{9}$.

Size of intracranial aneurysm is a key prognostic factor for rupture ${ }^{10}$. In general large aneurysms are more likely to rupture ${ }^{11-15}$. One large, multicenter trial suggested that aneurysms $10 \mathrm{~mm}$ or larger had a $1 \%$ annual risk of rupture, with smaller aneurysms having a much smaller risk of rupture. There seems to be a general agreement that the unruptured aneurysm e" $10 \mathrm{~mm}$ in diameter should be treated surgically ${ }^{16}$. Recent studies, including the prospective arm of the International Study of Unruptured Intracranial Aneurysms (ISUIA) suggest that aneurysms smaller than $10 \mathrm{~mm}$ have higher rates of rupture than previously predicted ${ }^{17}$.

Age and sex also influences on size of aneurysms 18,19. Site of aneurysm also impact on size of ruptured intracranial aneurysms (RIAs) ${ }^{20,21}$. The size at which aneurysms rupture appears to be smaller in those patients with the combination of hypertension and smoking than in those with either risk factor alone 22 .

Recently, unruptured intracranial aneurysms (UIAs) are increasingly detected due to the increased availability and improved sensitivity of noninvasive imaging technique ${ }^{23}$. Unruptured intracranial aneurysms (UIAs) are common, with autopsy studies placing their prevalence at approximately 2 to $8 \% 24,25$.

The ISUIA 2 study concluded that aneurysms $<7$ $\mathrm{mm}$ in size in the anterior circulation have an annual rupture risk of $0-0.1 \%$ per year ${ }^{16}$. But there are many studies that contradict with this study. The natural history of small un-ruptured aneurysms $(<5$ $\mathrm{mm}$ in diameter) without surgical treatment and found that the annual rupture rate was $0.8 \%$ for 380 aneurysms followed up for a mean of 13.8 months ${ }^{26}$. The annual bleeding rate was $1.92 \%$ $27,1.3 \%^{28}, 1.5^{29}$ and $2.3 \%^{30}$.

Several studies have shown that the decision to treat un-ruptured aneurysms should not be based on aneurysm size alone ${ }^{31-34}$. A study suggest that treatment of UIAs smaller than $7 \mathrm{~mm}$ in hypertensive patients and smokers may be beneûcial ${ }^{22}$.

The aim of this study is to find out the effect of risk factors on size of ruptured aneurysms, to assess the critical size at which most of aneurysms ruptured. So that we can able to draw a conclusion that a critical sized un-ruptured aneurysms with risk factors should consider either microsurgery or coiling.

\section{Materials and Methods:}

This was an observational, cross-sectional study. Forty four patients with aneurysmal subarachnoid haemorrhage admitted in Department of Neurology and Neurosurgery, Dhaka medical college hospital $(\mathrm{DMCH})$ were included for the study following proposed inclusion and exclusion criteria.

Following admission, patients with SAH was diagnosed clinically and was confirmed by CT scan of head or by lumber puncture (LP) in CT scan negative cases. Non-Aneurysmal SAH, Other than saccular aneurysms (Fusiform, traumatic and mycotic aneurysm) and arterio-venous malformation associated aneurysm were excluded.

A written informed consent was taken from each patient or their guardians. History regarding demographic profile (age, sex, marital status, education, socioeconomic level, family details); risk 
factors (hypertension, prior history of SAH, smoking habit \& alcohol, drug abuse) and clinical presentation was noted on the questionnaire.

The aneurysm size, site of location and aneurysm multiplicity was assessed by three-dimensional rotational digital subtraction angiography (DSA).

The location of the aneurysm was classified as follows: A) anterior circulation and B) posterior circulation. Multiplicity of aneurysm is defined in this study as the occurrence of two or more than two aneurysms.

Smokers were divided into smoker and never smokers; current and past smokers were included as smoker. Patients who consumed alcohol were classiûed as heavy $(30 \mathrm{ml} /$ day or more) or light drinkers (less than $30 \mathrm{ml} /$ day).

Hypertension was deûned if it had been diagnosed before admission. If systolic BP e"140 $\mathrm{mm} \mathrm{Hg}$ and Diastolic BPe"90 mmHg was diagnosed as hypertensive. Hypertensive patients were divided into 2 groups, those who took antihypertensive medication regularly (medicated group) and those who either took it irregularly or not at all (poorly controlled group). Blood pressure readings at admission or during subsequent hospitalization was taken into account because it is considered to be reûective of initial or subsequent clinical conditions. A history of SAH was recorded separately from other cerebrovascular diseases (CVD) in both the patient's and his or her family medical history.

Hunt and Hess grading was recorded from patient history and examination. Subjects with incomplete data was excluded. The data was analysed using standard statistical procedures.

The statistical analysis was performed using SPSS software v. 26.0. Continuous parameters were expressed as mean $\pm S D$ and categorical parameters as percentage. Differences between groups were analysed using Student t-test for metric variables and Chi-square test for ordinal or nominal scaled variables. The correlation between aneurysm size and risk factors were evaluated by one-way analysis of variance (ANOVA). Analysis of variance (univariate ANOVA) was among three groups. Statistical significance was defined as $\mathrm{p}<0.05$ ( $\mathrm{Cl} \% 0.95)$.

\section{Results:}

The study was conducted to assess the impact of risk factors on the size of ruptured intracranial aneurysms. Total 44 cases of subarachnoid hemorrhage were enrolled in this study. The mean age of the study population was $49.24 \pm 11.5$. About half of the population were within 51-60 years.

Out of 44 population, $54.5 \%$ were female. The male female ratio was 1:1.2. Presentation of subarachnoid hemorrhage in this study was, $93.2 \%$ population were presented with headache, $90.9 \%$ with vomiting, $81.8 \%$ had neck stiffness, $52.3 \%$ were unconscious, $15.9 \%$ had seizure, and $15.9 \%$ hemiplegia. In this study $59.1 \%$ were hypertensive, $47.73 \%$ were smoker, $15.9 \%$ were alcoholic and were light drinker, $6.8 \%$ were substances abuser and $11.4 \%$ had positive family history of SAH. $43.2 \%$ of population were in Hunt and Hess scale 2 . In this study, aneurysms mean size was $5.72 \pm 4.010 \mathrm{~mm}$. According to International Study on Un-ruptured Intracranial Aneurysms (ISUIA), $65.9 \%$ aneurysm size were $3-7 \mathrm{~mm}, 20.5 \%$ were $8-12 \mathrm{~mm}, 9.1 \%$ were below $3 \mathrm{~mm}$.

Table-I

Distribution of the study patients by aneurysms size $(n=44)$

\begin{tabular}{lcc}
\hline & Frequency & Percentage \\
\hline$<10 \mathrm{~mm}$ & 41 & 93.2 \\
$>10 \mathrm{~mm}$ & 3 & 6.8 \\
$<7 \mathrm{~mm}$ & 33 & 75.0 \\
$>7 \mathrm{~mm}$ & 11 & 25.0 \\
$<5 \mathrm{~mm}$ & 22 & 50.0 \\
$>5 \mathrm{~mm}$ & 22 & 50.0 \\
\hline
\end{tabular}

In table-I, $93.2 \%$ of aneurysms were below $10 \mathrm{~mm}$, $75.0 \%$ were below $7 \mathrm{~mm}$ and $50.0 \%$ below $5 \mathrm{~mm}$.

Table-II

Aneurysm size relation with hypertension $(n=44)$

\begin{tabular}{llcc}
\hline & \multicolumn{3}{c}{ Hypertension } \\
& $\begin{array}{l}\text { Hypertensive } \\
(n=26)\end{array}$ & $\begin{array}{c}\text { Normotensive } \\
(n=18)\end{array}$ & p-value \\
& Mean $\pm S D$ & Mean $\pm S D$ & \\
\hline Aneurysm & $4.68 \pm 2.69$ & $7.23 \pm 5.10$ & 0.037 \\
size $(\mathrm{mm})$ & & & \\
\hline
\end{tabular}

Table-II shows, size of ruptured aneurysm is small in hypertensive population and is significant $(P$ value 0.037 ) 
Table-III

Aneurysm size relation with smoking $(n=44)$

\begin{tabular}{lccc}
\hline & & Smoking status & \\
& $\begin{array}{c}\text { Smoker }(n=21) \\
\text { Mean } \pm S D\end{array}$ & Never smoker $(n=23)$ & p-value \\
& $4.18 \pm 1.74$ & Mean $\pm S D$ & \\
\hline Aneurysm size $(\mathrm{mm})$ & & $7.13 \pm 4.93$ & 0.013 \\
\hline
\end{tabular}

Table-III showsaneurysm size were $4.18 \pm 1.74 \mathrm{~mm}$ in smoker which is significantly ( $\mathrm{P}$ value -0.013 ) smaller than never smoker.

Table-IV

Aneurysm size relation with hypertension and smoking $(n=26)$

\begin{tabular}{llccc}
\hline Hypertension & $\mathrm{N}$ & Mean \pm SD & p-value & \\
\hline Yes & Smoker & 14 & $3.36 \pm 1.35$ & 0.004 \\
& Never smoker & 12 & $6.22 \pm 3.07$ & \\
\hline
\end{tabular}

Table-IV shows mean aneurysm size in hypertensive smoker population was $3.36 \pm 1.35 \mathrm{~mm}$ which is significantly ( $p$-value-0.004) smaller than hypertensive non-smoker.

Table-V

Aneurysm size relation with presence of risk factors $(n=44)$

\begin{tabular}{lccc}
\hline Risk factors & $\mathrm{N}$ & Mean $\pm S D$ & $\mathrm{p}$-value \\
\hline One risk factor & 11 & $8.32 \pm 6.84$ & 0.063 \\
Two risk factors & 17 & $5.26 \pm 1.86$ & \\
Three risk factors & 13 & $4.79 \pm 2.05$ & \\
$>$ Three risk factors & 3 & $2.85 \pm 1.43$ & \\
\hline
\end{tabular}

Table-V shows aneurysm size was dependent to presence of number of risk factors. More risk factors had small aneurysm.

\section{Discussion:}

The study was conducted to assess the impact of risk factors on the size of ruptured intracranial aneurysms. Total 44 cases of subarachnoid hemorrhage were enrolled in this study. The mean age of the study sample was $49.24 \pm 11.5$ years. About half of the population were within $51-60$ years. This is consistent with Reaz Mahmud et al where the average age was $48.24 \pm 9.26^{35}$. Another two studies conducted in Bangladeshthe mean age was $45.00 \pm 9.4$ and 45.9 years $^{36,37}$. In an epidemiological study done in India had shown average age of subarachnoid hemorrhage in their population was 49.63 years $^{38}$. Worldwide the mean age of aneurysmal rupture is in the range of 50 to 55 years. The mean age of this study coincides with the both worldwide and sub-continent.

Subarachnoid hemorrhage (SAH) is a disease with definite female preponderance. In this study $54.5 \%$ were female. The male female ratio was $1: 1.2$. The ratios of men to women were constant at approximately $1.2: 1^{39}, 1: 1.5^{40}$ and $1: 1.3^{41}$. A Bangladeshi study shows the male female ratio was $1: 1.6^{35}$.

93.2\% population were presented with headache, $90.9 \%$ with vomiting, $81.8 \%$ had neck stiffness, $52.3 \%$ were unconscious, $15.9 \%$ had seizure, and $15.9 \%$ hemiplegia. According to a Bangladeshi study, headache, neck rigidity and vomiting was invariably $(100 \%)$ complained by the patients at the onset. Two-thirds $(66.7 \%)$ of the patients were unconscious at presentation and $10 \%$ exhibited cranial nerve palsy ${ }^{36}$.

In this study $59.1 \%$ were hypertensive, $47.73 \%$ were smoker, $15.9 \%$ were alcoholic and were light drinker, $6.8 \%$ were substances abuser and $11.4 \%$ had positive family history of SAH. In Bangladesh a study of thirty SAH population revealed $44 \%$ of the patients had smoking habit and nearly half $(46.7 \%)$ had hypertension ${ }^{37}$. Another study was 
conducted at Dhaka medical college and Hospital showed hypertension, smoking, diabetes mellitus and family history of SAH were found in $46.6 \%$, $43.3 \%, 10.0 \%$ and $6.7 \%$ respectively ${ }^{42}$. Presence of risk factors in study population were more or less same with Bangladeshi research. An international study showed hypertension was identified in $52 \%{ }^{24}$.

In this study, mean size of ruptured aneurysms was $5.72 \pm 4.010 \mathrm{~mm}$. According to International Study on Un-ruptured Intracranial Aneurysms (ISUIA) classification, $65.9 \%$ aneurysm size were $3-7 \mathrm{~mm}$, $20.5 \%$ were $8-12 \mathrm{~mm}, 9.1 \%$ were below $3 \mathrm{~mm}$. Many studies showed the mean size of aneurysms were $5.59 \pm 29 \mathrm{~mm}^{27}, 6.6 \pm 2.7 \mathrm{~mm}^{35}, 5.8 \mathrm{~mm}^{43}$, $5 \pm 1.9 \mathrm{~mm}^{44}$ and $5.0 \mathrm{~mm}^{45}$. A total of 64 studies with 10873 intracranial aneurysms mean ruptured intracranial aneurysm size was $6.99 \pm 4.14 \mathrm{~mm}^{46}$. The mean aneurysm size of this study is similar to findings in the national and international literature.

In this study shows $93.2 \%$ of aneurysms were below $10 \mathrm{~mm}, 75.0 \%$ were below $7 \mathrm{~mm}$ and $50.0 \%$ below $5 \mathrm{~mm}$. About $91 \%^{21}, 80 \%^{36}, 85.6 \%{ }^{47}$ and $93.2 \% 48$ were $<10 \mathrm{~mm}$ in size. A study showed $75 \%$ of ruptured aneurysms $<7 \mathrm{~mm}^{48}$. A study found $13 \%$ of the ruptured aneurysms they studied were less than $5 \mathrm{~mm}$ in diameter and $57 \%$ were between 5 and $10 \mathrm{~mm}$ in diameter ${ }^{40}$. More than half of the ruptured aneurysms measured less than $7 \mathrm{~mm}^{48}$.In this study most of the aneurysms size were below $10 \mathrm{~mm}$ diameter which is similar to that of many literatures.

A study believes aneurysms shrink after rupture, so the calculated size of ruptured aneurysm does not reflect their size before rupture ${ }^{17}$. But there are lots of studies that established size of ruptured aneurysms do not change rather size increase 29 , 49- 51.

In this study, 35.4\% were ACom aneurysms, $29.2 \%$ were PCom aneurysms, $16.7 \%$ were MCA bifurcation. $87.5 \%$ aneurysms were in anterior circulation and $12.5 \%$ were in posterior circulation which is consistent with findings of both national and international publications 42,52 .

In this study aneurysms size was smaller in older female patient which is consistent with Young-
GyunJeong et $\mathrm{al}^{18}$. It is due to effect of estrogen hormone.

In this study mean aneurysm size in male was $5.67 \pm 3.09 \mathrm{~mm}$ and in female was $5.77 \pm 4.71 \mathrm{~mm}$. Aneurysms size was $6.17 \mathrm{~mm}$ for males, and 5.91 $\mathrm{mm}$ for females ${ }^{53}$. A study showed gender-specific risk factor distribution did not differ significantly among males and females ${ }^{22}$.

In this study mean aneurysm size were more in case of positive family history population. It is different from other literatures ${ }^{18}$. This difference may be due to poor number of positive family history population in this study.

In this study mean aneurysm size was $4.68 \pm 2.69$ $\mathrm{mm}$ in hypertensive patients and in normotensive population it was $7.23 \pm 5.10 \mathrm{~mm}$. Size of ruptured aneurysm is small in hypertensive population and is significant ( $p$-value 0.037). There was a significant correlation between hypertension and the rupture of aneurysms smaller than 5 $\mathrm{mm}^{54}$. Hypertensive patients $(6.27 \pm 3.28 \mathrm{~mm})$ had signiûcantly smaller ruptured intracranial aneurysms than normotensive $(8.08 \pm 4.73 \mathrm{~mm})^{22}$.

In this study aneurysms mean size was $4.18 \pm 1.74$ $\mathrm{mm}$ in case of smoker and $7.13 \pm 4.93 \mathrm{~mm}$ in never smoker. Aneurysm size was significantly ( $p$-value 0.013 ) smaller in case of smoker. A study showed, patients with a history of cigarette smoking had only slightly smaller ruptured aneurysms $(7.61 \pm 4.29 \mathrm{~mm})$ compared to patients with no risk factors $(8.08 \pm 4.73 \mathrm{~mm})^{22}$.

In this study mean size of aneurysm in male hypertensive population $5.04 \pm 3.57 \mathrm{~mm}$ which is smaller than male normotensive patient. In case of female hypertensive population mean size is $4.41 \pm 1.90 \mathrm{~mm}$ which is smaller than female normotensive patient and also from male hypertensive patient. In this study, male smoker had mean aneurysm size $4.65 \pm 1.79 \mathrm{~mm}$ which was significantly smaller than male never smoker ( $p$ value 0.040 ) and in female smoker mean aneurysm size was $3.42 \pm 1.44 \mathrm{~mm}$ which was also smaller than female non-smoker and male smoker.

In this study mean aneurysm size in hypertensive smoker population was significantly ( $p$-value-0.004) 
smaller than hypertensive non-smoker. A study of 373 ruptured intracranial aneurysms and showed that the sizes of the ruptured IAs were significantly smaller in patients with a combined history of hypertension and cigarette smoking than those with hypertension alone, smoking alone or nonhypertension and non-smoking 22 .

In this study population with one risk factor had mean aneurysm size of $8.32 \pm 6.84 \mathrm{~mm}$, two risk factors had $5.26 \pm 1.86 \mathrm{~mm}$, three risk factors had $4.79 \pm 2.05 \mathrm{~mm}$ and more than three risk factors had 2.85 \pm 1.43 . So, aneurysm size was dependent to presence of number of risk factors. More risk factors had smaller aneurysm which is consistent withNimaEtminan et al in which presence of one risk factor had smaller size than no risk factors and two risk factors had smaller size than one risk factor 22 .

\section{Conclusion:}

The present analysis demonstrates that hypertension, smoking have a significant influence on the size of ruptured aneurysms in patients suffering from $\mathrm{SAH}$. Other risk factors female sex, age, positive family history have also impact on aneurysm size but lesser extent. But when one risk factor is associated with other factors it decreases the size of ruptured aneurysm. In case of more the risk factors, the size become smaller. As a consequence, data strongly suggest that patients with these risk factors have a lower threshold of aneurysm rupture than patients without risk factors. Therefore, Size cannot be considered the only factor to determine treatment recommendations rather the history of hypertension, cigarette smoking, female sex, age and positive family history should be considered in the assessment of treatment of un-ruptured intracranial aneurysms.

\section{References:}

1. van Gijn J, Rinkel GJ. Subarachnoid haemorrhage: diagnosis, causes and management. Brain. 2001 Feb 1;124(2):24978.

2. Linn FHH, Rinkel GJ, Algra A, Van Gijn J : Incidence of $\mathrm{SAH}$; role of region, year and rate of computed tomography, a metaanalysis, stroke 1991, 27, 625-29.
3. Van Gijn J, Kerr RS, Rinkel GJ. Subarachnoid haemorrhage. The Lancet. 2007 Jan 27;369(9558):306-18.

4. Hernesniemi J, Vapalahti M, Niskanen M, Tapaninaho A, Kari A, Luukkonen M, Puranen M, Saari T, Rajpar M. One-year outcome in early aneurysm surgery: a 14years experience. Actaneurochirurgica. 1993 Mar 1;122(1-2):1-0.

5. Wiebers DO, Torner JC, Meissner I. Impact of unruptured intracranial aneurysms on public health in the United States. Stroke. 1992 Oct;23(10):1416-9.

6. Bhat AR, Wani MA, Kirmani AR, Ramzan AU, Alam S, Raina T, Jain AK, Arif S, Laharwal $M A, M K$ B. High incidence of intracranial aneurysmal subarachnoid hemorrhage (SAH) in Kashmir, India. Biomedial research, 2012, 23(1)1

7. Colledge NR, Walker BR, Ralston S, Davidson S. Davidson s principles and practice of medicine. Churchill Livingstone/ Elsevier,; 2010.

8. Feigin V, Parag V, Lawes CM, Rodgers A, Suh I, Woodward M, Jamrozik K, Ueshima H. Smoking and elevated blood pressure are the most important risk factors for subarachnoid hemorrhage in the Asia-Pacific region: an overview of 26 cohorts involving 306620 participants. Stroke. 2005 Jul 1;36(7):1360-5.

9. Kubota M, Yamaura A, Ono J. Prevalence of risk factors for aneurysmal subarachnoid haemorrhage: results of a Japanese multicentre case control study for stroke. British journal of neurosurgery. 2001 Jan 1;15(6):474-8.

10. Rosenørn J. Unfavorable prognostic factors in patients with intracranial aneurysms and the possibilities to improve the overall outcome. ProgClinNeurosci. 1988;2:179-86.

11. Wiebers DO, Whisnant JP, O'Fallon WM. The natural history of unruptured intracranial aneurysms. New England Journal of Medicine. 1981 Mar 19;304(12):696-8. 
12. Crompton MR. Mechanism of growth and rupture in cerebral berry aneurysms. British medical journal. 1966 May 7;1(5496):1138.

13. Eskesen V, Rosenørn J, Schmidt K. The influence of unruptured intracranial aneurysms on life expectancy in relation to their size at the time of detection and to age. British journal of neurosurgery. 1988 Jan 1;2(3):379-84

14. Wiebers DO, Whisnant JP, Sundt TM, O'Fallon WM. The significance of unruptured intracranial saccular aneurysms. Journal of neurosurgery. 1987 Jan 1;66(1):23-9.

15. Whisnant JP, Phillips 2nd LH, SundtJr TM. Aneurysmal subarachnoid hemorrhage: timing of surgery and mortality. InMayo Clinic Proceedings 1982 Aug 1 (Vol. 57, No. 8, pp. 471-475).

16. International Study of Unruptured Intracranial Aneurysms Investigators. Unruptured intracranial aneurysms-risk of rupture and risks of surgical intervention. New England Journal of Medicine. 1998 Dec 10;339(24):1725-33.

17. Wiebers DO, Whisnant JP, Huston 3rd J, Meissner I, Brown Jr RD. Piepgras DG, Forbes GS, Thielen K, Nichols D, O'Fallon WM, Peacock J, Jaeger L, Kassell NF, Kongable-Beckman GL, Torner JC. Unruptured intracranial aneurysms: Natural history, clinical outcome, and risks of surgical and endovascular treatment. Lancet. 2003;362:103-10.

18. Jeong YG, Jung YT, Kim MS, Eun CK, Jang $\mathrm{SH}$. Size and location of ruptured intracranial aneurysms. Journal of Korean Neurosurgical Society. 2009 Jan;45(1):11.

19. Choi JH, Park HS. The incidence and characteristics of patients with small ruptured aneurysms $(<5 \mathrm{~mm})$ in subarachnoid hemorrhage. Journal of Korean Neurosurgical Society. 2017 Jul;60(4):424.

20. Korja M, Kivisaari R, Jahromi BR, Lehto $H$. Size and location of ruptured intracranial aneurysms: consecutive series of 1993 hospital-admitted patients. Journal of neurosurgery. 2016 Dec 2;127(4):748-53.

21. HP Lai, KM Cheng, Simon CH, Yu KM, Au Yeung, YL Cheung, CM Chan, WS Poon, WM LuiSize, location, and multiplicity of ruptured intracranial aneurysms in the Hong Kong Chinese population with subarachnoid haemorrhage. Hong Kong Med J. 2009 Aug;15(4):262-6.

22. Etminan N, Beseoglu K, Steiger HJ, Hänggi $D$. The impact of hypertension and nicotine on the size of ruptured intracranial aneurysms. Journal of Neurology, Neurosurgery \& Psychiatry. 2011 Jan 1;82(1):4-7.

23. Keedy A. An overview of intracranial aneurysms. McGill Journal of Medicine: MJM. $2006 \mathrm{Jul} ; 9(2): 141$.

24. Inagawa T, Hirano A. Autopsy study of unruptured incidental intracranial aneurysms. Surgical neurology. 1990 Dec 1;34(6):361-5.

25. Li MH, Chen SW, Li YD, Chen YC, Cheng YS, Hu DJ, Tan HQ, Wu Q, Wang W, Sun ZK, Wei XE. Prevalence of unruptured cerebral aneurysms in Chinese adults aged 35 to 75 years: a cross-sectional study. Annals of internal medicine. 2013 Oct 15;159(8): 514-21.

26. YONEKURA M. Small unruptured aneurysm verification (SUAVe study, Japan). Neurologia medico-chirurgica. 2004;44(4):213-4.

27. Asari S, Ohmoto T. Natural history and risk factors of unruptured cerebral aneurysms. Clinical neurology and neurosurgery. 1993 Sep 1;95(3):205-14.

28. Juvela S, Porras M, Poussa K. Natural history of unruptured intracranial aneurysms: probability of and risk factors for aneurysm rupture. Journal of neurosurgery. 2008 May 1;108(5):1052-60.

29. Suga M, Yamamoto $Y$, Sunami N, Abe T, Michiue H. Rupture of previously documented asymptomatic unruptured aneurysmsaneurysm size: risk factor for aneurysm rupture. No shinkeigeka. Neurological surgery. 2002 Jun;30(6):609-15. 
30. Yasui N, Suzuki A, Nishimura H, Suzuki K, Abe T. Long-term follow-up study of unruptured intracranial aneurysms. Neurosurgery. 1997 Jun 1;40(6):1155-60.

31. Forget Jr TR, Benitez R, Veznedaroglu E, Sharan A, Mitchell W, Silva M, Rosenwasser $\mathrm{RH}$. A review of size and location of ruptured intracranial aneurysms. Neurosurgery. 2001 Dec 1;49(6):1322-6.

32. Juvela S, Porras M, Poussa K. Natural history of unruptured intracranial aneurysms: probability of and risk factors for aneurysm rupture. Journal of neurosurgery. 2000 Sep 1;93(3):379-87.

33. Matsumoto K, Akagi K, Abekura M, Nakajima $\mathrm{Y}$, Yoshiminie T. Investigation of the surgically treated and untreated unruptured cerebral aneurysms of the anterior circulation. Surgical neurology. 2003 Dec 1;60(6):516-22.

34. Ujiie H, Sato K, Onda H, Oikawa A, Kagawa M, Takakura K, Kobayashi N. Clinical analysis of incidentally discovered unruptured aneurysms. Stroke. 1993 Dec;24(12): 1850-6.

35. Mahmud R, Habib M, Khan SU, Khan A. Risk Factors and Morphological Differences of Ruptured Saccular Aneurysm in Different Sites of Anterior Circulation in Patients Presenting with Subarachnoid Haemorrhage. Journal of National Institute of Neurosciences Bangladesh. 2017;3(1):21-8.

36. Hasan MN, Hoque MA, Rahman KM, Hoque MH, Amin MR, Haque M, Joarder Al, Helal $A H$. Clinical and digital subtraction angiographic (DSA) evaluation of patients of subarachnoid haemorrhage (SAH) in a tertiary level hospital. Bangladesh Medical Journal. 2015;44(3):125-9.

37. Alam S, Rahman A, Uddin AW, Islam KT, Mojumder MR, Rahman M, Ahmed A, Obaida AA, Haque SU, Uddin MN. Intracranial Aneurysms: Acute VS Delayed Surgery-An Analysis of 52 Cases. Bangladesh Journal of Neuroscience. 2012;28(1):29-37.
38. Shingare A, Nadkar MY, Singh R. Study of patient characteristics/profile and factors determining the (immediate) outcome in spontaneous subarachnoid hemorrhage. J Assoc Physicians India. 2011 Aug;59:505-8.

39. Hamdan A, Barnes J, Mitchell P. Subarachnoid hemorrhage and the female sex: analysis of risk factors, aneurysm characteristics, and outcomes. Journal of neurosurgery. 2014 Dec 1;121(6):1367-73.

40. Kassell NF, Torner JC. Size of intracranial aneurysms. Neurosurgery. 1983 Mar 1;12(3):291-7.

41. D'Souza S. Aneurysmal subarachnoid hemorrhage. Journal of neurosurgical anesthesiology. $2015 \mathrm{Jul} ; 27(3): 222$.

42. Islam M, Hasan M, Hakim M, Khan SU, Rahman KM, Mohammad QD. Digital Subtraction Angiography Findings in Aneurysmal Subarachnoid Haemorrhage: Experience of 30 Cases in Bangladesh. Journal of National Institute of Neurosciences Bangladesh. 2016;2(2):51-4.

43. Swartbooi A, Meyer C, de Vries C. Digital subtraction angiography findings and population demographics of patients with subarachnoidal haemorrhage and subsequent causative aneurysms at Universitas Academic Hospital, Bloemfontein. SA Journal of Radiology. 2016;20(1):1-6.

44. Dhar S, Tremmel M, Mocco J, Kim M, Yamamoto J, Siddiqui AH, Hopkins LN, Meng $\mathrm{H}$. Morphology parameters for intracranial aneurysm rupture risk assessment. Neurosurgery. 2008 Aug 1;63(2):185-97.

45. AlMatter M, Bhogal P, Pérez MA, Schob $S$, Hellstern V, Bäzner H, Ganslandt O, Henkes $\mathrm{H}$. The Size of Ruptured Intracranial Aneurysms. Clinical Neuroradiology. 2019 Mar 8;29(1):125-33.

46. Mokin M, Waqas M, Gong A, Chin F, Rai H, Vakharia K, RajabzadehOghaz H, Snyder KV, Davies J, Levy El, Meng H. What Size Cerebral Aneurysms Rupture? A Systematic Review and Meta-Analysis of Literature. 
Neurosurgery. 2019 Sep 1;66 (Supplement_1): nyz310_664.

47. Forget Jr TR, Benitez R, Veznedaroglu E, Sharan A, Mitchell W, Silva M, Rosenwasser $\mathrm{RH}$. A review of size and location of ruptured intracranial aneurysms. Neurosurgery. 2001 Dec 1;49(6):1322-6.

48. van Donkelaar CE, Bakker NA, Veeger NJ, Uyttenboogaart M, Metzemaekers JD, Eshghi O, Mazuri A, Foumani M, Luijckx GJ, Groen RJ, van Dijk JM. Prediction of outcome after subarachnoid hemorrhage: timing of clinical assessment. Journal of neurosurgery. 2017 Jan 1;126(1):52-9.

49. Rahman M, Ogilvy CS, Zipfel GJ, Derdeyn $\mathrm{CP}$, Siddiqui AH, Bulsara KR, Kim LJ, Riina HA, Mocco J, Hoh BL. Unruptured cerebral aneurysms do not shrink when they rupture: multicenter collaborative aneurysm study group. Neurosurgery. 2011 Jan 1;68(1): 155-61.

50. Yasui N, Magarisawa S, Suzuki A, Nishimura $\mathrm{H}$, Okudera T, Abe T. Subarachnoid hemorrhage caused by previously diagnosed, previously unruptured intracranial aneurysms: a retrospective analysis of 25 cases. Neurosurgery. 1996 Dec 1;39(6):1096-101.

51. Kataoka K, Taneda M, Asai T, Yamada Y. Difference in nature of ruptured and unruptured cerebral aneurysms. The Lancet. 2000 Jan 15;355(9199):203.

52. Froelich JJ, Neilson S, Peters-Wilke J, Dubey A, Thani N, Erasmus A, Carr MW, Hunn AW. Size and location of ruptured intracranial aneurysms: a 5-year clinical survey. World neurosurgery. 2016 Jul 1;91:260-5.

53. Zhao L, Zhang L, Zhang X, Li Z, Tian L, Wang YX. An analysis of 1256 cases of sporadic ruptured cerebral aneurysm in a single Chinese institution. PloS one. 2014 Jan 15;9(1):e85668.

54. Ohashi Y, Horikoshi T, Sugita M, Yagishita T, Nukui $\mathrm{H}$. Size of cerebral aneurysms and related factors in patients with subarachnoid hemorrhage. Surgical neurology. 2004 Mar 1;61(3):239-45. 